\title{
REVIEW
}

\section{Keratoconus Treatment Algorithm}

\author{
Konstantinos D. Andreanos - Kate Hashemi - Myrsini Petrelli •
}

Konstantinos Droutsas · Ilias Georgalas · George D. Kymionis

Received: June 26, 2017 / Published online: July 28, 2017

(C) The Author(s) 2017. This article is an open access publication

\section{ABSTRACT}

Keratoconus management has significantly changed over the last two decades. The advent of new interventions such as cornea cross-linking, intrastromal corneal ring segments, and combined treatments provide corneal clinicians a variety of treatment options for the visual rehabilitation of keratoconus patients. This review summarizes current evidence for these treatments and highlights their place in keratoconus management while new promising emerging therapies are being investigated.

Keywords: Accelerated cross-linking; Corneal cross-linking; CXL plus; Epi-on cross-linking; Intrastromal corneal ring segments; Keratoconus treatment algorithm

Enhanced content To view enhanced content for this article go to http://www.medengine.com/Redeem/ D7F8F0606EE424AF.

K. D. Andreanos $(\bowtie) \cdot$ M. Petrelli · K. Droutsas . I. Georgalas · G. D. Kymionis

1st Department of Ophthalmology, 'G. Gennimatas Hospital', National and Kapodistrian University of Athens, Athens, Greece

e-mail: coandre80@icloud.com

K. Hashemi

Faculty of Biology and Medicine, Jules Gonin Eye Hospital, University of Lausanne, Lausanne, Switzerland

\section{BACKGROUND}

\section{Methods of Literature Research}

Medline and PubMed databases were used to search the keywords keratoconus, contact lenses, intrastromal corneal ring segments, cornea transplantation, and cornea cross-linking from 1990 to 2017. Detailed search was limited to English-language manuscripts or at least available abstracts. The authors reviewed a total of 393 abstracts. From these, 126 articles were considered of clinical relevance to the subject and were included in the review. This article is based on previously conducted studies and does not involve any new studies of human or animal subjects performed by any of the authors.

\section{Definition}

Keratoconus is a progressive, bilateral, asymmetric, ectatic disease which causes progressive corneal thinning and protrusion of the cornea leading to irregular astigmatism and visual deterioration [1]. The term keratoconus derives from the Greek words kerato-idis (cornea) and konos (cone). John Nottingham is considered the first author to describe keratoconus and its associations [2]. Interestingly, his proposed treatment algorithm has many similarities to the one used today-optical devices being the 
management option of choice in the mild stages with surgery being a last resort [3].

A recent project using a modified Delphi method called on experts from around the world to elucidate the controversies that exist regarding keratoconus and other ectatic disorders [4]. Thirty-six ophthalmologists shared their expertise to come to a consensus regarding definition, diagnostic methods, and management options for keratoconus and other ectatic diseases. As a result, keratoconus was classified under the term "primary ectatic disease" as opposed to other corneal pathologies which result in cornea thinning without having an ectatic component.

\section{Frequency}

Keratoconus typically commences at puberty and tends to progress until the third or fourth decade of life [5]. The progression rate of keratoconus varies between individuals and is usually higher in younger patients. The disease tends to stabilize approximately 20 years following initial presentation [5].

The reported prevalence of keratoconus is highly variable, as it is influenced by many factors, such as the selected cohort of patients, the geographic location, and the criteria used for diagnosis. More specifically, prevalence figures vary worldwide and can range from $0.0003 \%$ in Russia [6] to $2.3 \%$ in India [7], while the most frequently cited prevalence for keratoconus in the literature is $0.054 \%$ in Minnesota in the USA [8]. The widespread use of corneal topography and common diagnostic criteria is expected to result in increased reported prevalence and incidence figures. In a recent epidemiologic study in the Netherlands, the annual incidence and prevalence of keratoconus were reported to be five- to tenfold higher than previously estimated [9].

Keratoconus occurs in both genders [8]. No gender predominance has been reported in several studies, whereas recent reports have suggested a higher prevalence among male patients $[9,10]$.

\section{Risk Factors}

The etiology of keratoconus is multifactorial. Commonly reported risk factors for keratoconus include family history, ethnicity (Asian and Arabian), mechanical factors (e.g., eye rubbing, floppy eyelid), atopy, ocular allergy, Down syndrome, connective tissue disorders (Marfan syndrome, Ehlers-Danlos), and Leber's congenital amaurosis [4, 11].

\section{Morbidity}

Visual loss occurs primarily from irregular astigmatism and myopia due to corneal protrusion, and secondarily from corneal scarring. Corneal thinning usually occurs in the central cornea as well as the inferotemporal cornea [12]. Advanced keratoconus may rarely progress to corneal hydrops, so-called acute keratoconus, wherein breaks occur in the Descemet layer, at times associated with stromal clefts, that cause aqueous to enter the stroma, leading to stromal edema and potentially severe corneal scarring. Patients usually report a sudden loss of vision and some ocular discomfort in the affected eye accompanied by limited pain and conjunctival injection [12].

\section{Keratoconus Diagnosis}

Disease detection, especially at early stages, is essential particularly in preventing iatrogenic ectasia in patients with subclinical forms of keratoconus who undergo refractive surgery. Over the last decade, important improvements have been reported regarding the diagnosis and management of keratoconus [13]. Corneal topography and tomography (Scheimpflug imaging or anterior segment optical coherence tomography, OCT) are among the most useful technologies for the evaluation of the anterior and posterior corneal surfaces, as they can generate corneal thickness and elevation maps, and can provide epithelial imaging and analysis of the anterior segment [14-16]. Moreover, instruments evaluating the corneal biomechanics provide useful parameters for the diagnosis and monitoring of the disease. Technological advances have increased the demands for newer classifications systems, as older ones [e.g. Amsler-Krumeich classification system (Table 1)], although widely acceptable, 
Table 1 Amsler-Krumeich classification system

\begin{tabular}{ll}
\hline Stage & Findings \\
\hline 1 & Eccentric steepening \\
& Myopia, induced astigmatism, or both $<5.00 \mathrm{D}$ \\
& Mean central K readings $<48 \mathrm{D}$ \\
& Myopia, induced astigmatism, or both from 5.00 \\
& to $8.00 \mathrm{D}$ \\
& Mean central K readings $<53.00 \mathrm{D}$ \\
& Absence of scarring \\
& Corneal thickness $>400 \mu \mathrm{m}$ \\
& Myopia, induced astigmatism, or both from 8.00 \\
& to $10.00 \mathrm{D}$ \\
& Mean central K readings $>53.00 \mathrm{D}$ \\
& Absence of scarring \\
& Corneal thickness $300-400 \mu \mathrm{m}$ \\
& Refraction not measurable \\
& Mean central K readings $>55.00 \mathrm{D}$ \\
& Central corneal scarring \\
& Corneal thickness $<200 \mu \mathrm{m}$ \\
\hline &
\end{tabular}

$D$ diopter, $K$ keratometry

do not combine topographical and tomographical indicators or maps and biomechanical parameters. Valuable information has been provided for the diagnosis and monitoring of keratoconus through studies presenting classification systems based on combined topographical, tomographical, and biomechanical parameters $[13,15,17-20]$. Several newly developed pieces of software such as the Enhanced Reference Surface and the Belin-Ambrosio Enhanced Ectasia display can be employed to detect earlier changes [14].

\section{Keratoconus Progression}

According to the Global Consensus on Keratoconus and Ectatic Diseases, "ectasia progression" is defined by a consistent change in at least two of the following parameters [4]:
Table 2 Criteria used to establish keratoconus progression in cross-linking clinical trials [21]

\begin{tabular}{lc}
\hline $\begin{array}{l}\text { Steepest keratometry } \\
\left(K_{\max }\right)\end{array}$ & $>1 \mathrm{D}$ increase from baseline \\
$\begin{array}{l}\text { Flattest keratometry } \\
\left(K_{\min }\right)\end{array}$ & $>1 \mathrm{D}$ increase from baseline \\
Mean keratometry $\left(K_{\text {mean }}\right)$ & $>0.75 \mathrm{D}$ Increase from \\
& baseline \\
Corneal apex power & $>1 \mathrm{D}$ increase from baseline \\
Manifest spherical & $>0.5 \mathrm{D}$ difference from \\
equivalent & baseline \\
Central corneal thickness & $>2 \%$ decrease from baseline \\
\hline$D$ diopter
\end{tabular}

$D$ diopter

1. Steepening of the anterior corneal surface

2. Steepening of the posterior corneal surface

3. Thinning and/or an increase in the rate of corneal thickness change

However, most clinical trials examining corneal cross-linking efficacy use the criteria shown in Table 2 [21].

Progression of keratoconus usually results in deterioration of best spectacle-corrected visual acuity (BSCVA). Nevertheless, a decrease in both uncorrected visual acuity and BSCVA is not essential to document progression of keratoconus. Younger patients should be examined at shorter time intervals [4].

\section{CURRENT TREATMENT OPTIONS AND MANAGEMENT}

\section{Spectacles and Contact Lenses in Keratoconus}

Spectacles may be used in early keratoconic cases. It is often difficult to achieve satisfactory spectacle vision because of various disease factors, such as high irregular astigmatism and significant anisometropia. Contact lenses, on the other hand, can offer satisfactory vision by addressing refractive errors and anterior cornea irregularities in keratoconic patients [22]. 
The type of contact lenses prescribed depends on the stage of keratoconus [23]. Soft lenses, soft toric, or custom soft toric contact lenses may be adequate early in the disease to correct myopia, regular astigmatism, and mildly irregular astigmatism. As the disease progresses, rigid gas-permeable (RGP) lenses or various specialized lenses, such as hybrid lenses, piggyback, or scleral lenses, may be required [23].

Soft corneal contact lenses offer adequate vision, sufficient tear exchange, corneal oxygenation along with ease of handling and low rates of infection if handled properly. RGPs offer better vision than soft lenses in more advanced cases but are often associated with discomfort and foreign body sensation, difficulty with centration of the optics in highly decentered cone apices, and the inability of the lens to be properly fitted in some advanced cases [24].

Recent developments in lens material and design, however, have addressed these problems. In cases of RGP intolerance, both piggyback lens combination and hybrid lenses can improve wearing time [25]. The piggyback approach incorporates a corneal RGP lens over a soft silicone hydrogel lens, combining increased patient comfort with adequate visual performance. For example, a soft lens with high positive power (4D) improves centration of a rigid lens in case of a sagging cone.

Hybrid lenses consist of a central RGP lens and a soft peripheral skirt lens [25], thus combining the visual performance of a rigid lens with the comfort and stability of a soft lens. Scleral lenses are often reserved for advanced cases. Current scleral lenses offer good visual performance and comfort [26].

Advanced high oxygen-permeable lens materials and unique designs allow higher corneal oxygen supply and tear exchange. Customization has been advocated by the use of anterior segment OCT and various forms of corneoscleral profile measurement instruments, greatly improving lens tolerance and visual outcomes [27].

\section{Intrastromal Corneal Ring Segments}

Intrastromal corneal ring segments (ICRS) are medical devices made of synthetic material designed to alter the morphology and refractive power of the cornea. ICRS implantation is a safe and reversible technique that can achieve corneal flattening and improved visual outcomes. Several factors such as the type of ICRS, the insertion technique, and patient selection contribute to the final outcome [28].

Different types of ICRS are currently available, offering a variety in thickness, diameter, and ICRS profile (Table 3). Proper selection of the ICRS depends mainly on the refractive error, corneal thickness, and keratometry readings of the keratoconic patient. Smaller ring diameters offer increased flattening effects and are often used in patients with higher refractive errors [29].

Table 3 Characteristics of different types of ICRS

\begin{tabular}{lllllll}
\hline Name & Manufacturer & $\begin{array}{l}\text { Arc } \\
\mathbf{l e n g t h}\left({ }^{\circ}\right)\end{array}$ & $\begin{array}{l}\text { Thickness } \\
(\mathbf{m m})\end{array}$ & $\begin{array}{l}\text { Inner diameter } \\
(\mathbf{m m})\end{array}$ & $\begin{array}{l}\text { Outer } \\
\text { diameter }(\mathbf{m m})\end{array}$ & Profile \\
\hline Intacs & $\begin{array}{l}\text { Addition Technology Inc. } \\
\text { Sunnyvale, CA, USA }\end{array}$ & 150 & $0.25-0.45$ & 6.8 & 8.1 & Hexagonal \\
Kerarings & $\begin{array}{l}\text { Mediphacos Ltd, Belo Horizonte, } \\
\text { Brazil }\end{array}$ & $90-210$ & $0.15-0.35$ & 5.0 & 6.0 & Triangular \\
$\begin{array}{l}\text { Intacs } \\
\text { SK }\end{array}$ & $\begin{array}{l}\text { Addition Technology Inc. } \\
\text { Sunnyvale, CA, USA }\end{array}$ & 150 & $0.4-0.45$ & 6.0 & 7.3 & Oval \\
MyoRing & Dioptex GmbH, Linz, Austria & 360 & $0.15-0.35$ & $5.0-8.0$ & $5.0-8.0$ & Triangular \\
\hline
\end{tabular}


Proper patient selection is crucial to the final visual outcome of ICRS implantation. There are no general guidelines but most authors agree that patients should meet the following criteria:

- Corrected distance visual acuity below 0.9 in the decimal score

- Intolerance to contact lens use

- Absence of cornea scarring

The creation of channels deep into the cornea $(70-80 \%$ of total corneal thickness), where the segments will be inserted, can be achieved either by the mechanical technique or the use of femtosecond laser [30]. Femtosecond laser tunnel creation has enhanced safety in ICRS implantation by ensuring an accurate and precise depth of implantation and reducing the risk of operative and postoperative complications.

To date, there are no established nomograms for the procedure and most researchers use empirical data and subjective analysis. The number of segments implanted, the location of insertion, and the use of multiple segments of different styles vary among studies. Regarding the number of segments, Alio et al. reported that the number of implanted segments should be decided according to the topographic pattern of the keratoconus: in cases of central cones implantation of two segments offers optimum results, while in cases of inferior steepening one implant should suffice [31]. Siganos et al. reported satisfactory visual results after implantation of two segments of $160^{\circ}$ arc length while adjusting the thickness according to the patient's refractive error [32].

Likewise, there is no agreement concerning the location of the implant. Some authors report better visual outcomes when the corneal incision is made on the temporal side of the cornea, whereas others believe that the incision should be performed in the steepest meridian $[31,33]$.

Most authors report satisfactory results after ICRS implantation in terms of visual acuity and optical quality. It seems that patients with poor visual acuity at the time of surgery are more likely to benefit from the procedure [34, 35]. Furthermore, long-term results seem to depend on disease progression at the time of surgery, with stable forms demonstrating favorable outcomes over a longer period of time [35].
Keratoplasty: Penetrating Keratoplasty (PK)-Deep Anterior Lamellar

Keratoplasty (DALK)

Until recently, PK has been the treatment of choice for advanced forms of keratoconus. However, improvements in operative techniques have increased the popularity of DALK. The advantages of DALK over classic PK consist of lower rates of graft rejection, endothelial cell preservation, avoidance of an open-sky procedure, and shorter period of postoperative instillation of steroid agents, leading to lower incidence of postoperative cataract and glaucoma formation [36]. On the contrary, limitations of the method include the demanding surgical skills required for the performance of the DALK technique and the fact that it cannot be easily applied in corneas with scars, neovascularization, or previous hydrops [37].

Despite the popularity of DALK amongst corneal surgeons for keratoconus, there is a paucity of high-quality randomized controlled trials (RCTs) comparing the two techniques. The existing evidence confirms reduced rejection and refractive astigmatism with DALK but better visual outcomes with PK [38]. However, it seems that DALK properly performed provides the same visual outcomes as PK. In studies where reported DALK visual outcomes were inferior to $\mathrm{PK}$, this discrepancy has been attributed to incomplete stromal dissection and residual stroma over the Descemet membrane (DM). The poor visual outcomes seem to depend on the depth of the dissection (not revealing a bare $\mathrm{DM}$ ), rather than the regularity and smoothness of the residual stromal bed [38] as shown in a recent study which compared femtosecond laser-assisted descemetic and predescemetic lamellar keratoplasty [39].

Concerning complication rates, reported incidences of penetrating keratoplasty graft rejection range from $2.3 \%$ to $68 \%$ [40-42], though graft failure rate in these eyes tend to be less, thanks to immediate application of corticosteroid therapy [40]. DALK, on the other hand, spares transplantation of the endothelium, thus eliminating the possibility of endothelium rejection. However, epithelial, stromal, and mixed epithelial and stromal graft 
rejection can occur at a rate of $8-10 \%[43,44]$. Graft survival is projected to be longer with DALK [38]. Borderie et al. using a joint regression model predicted an average life span for PK grafts of 17.9 years, compared to 49 years with DALK [45]. The most common complication in DALK surgery is perforation of the Descemet membrane during surgery [46]. The risk is less in elderly patients, who tend to have a thicker Descemet membrane. Depending on the stage of the surgery it may be necessary to convert to PK. Several authors have addressed the problem and proposed variations in the technique that reduce the rate of this complication $[47,48]$. Recently, the creation of tunnels using femtosecond laser as a pretreatment for the creation of a big bubble has been proposed by Diakonis et al. [49], while Siebelmann et al. reported the increased safety of intraoperative use of OCT in DALK [50].

Femtosecond laser (FSL) application has shown promise in improving postoperative outcomes in both techniques [51,52]. In PK, the FSL can achieve a greater precision in cutting either the donor or the recipient cornea, minimizing misalignments and increasing the stability of the wound [51]. Furthermore, FSL can be used to create different wound configurations, not achievable with conventional trephine techniques, such as the top-hat, mushroom, or zig-zag configurations [52]. Reduced postoperative astigmatism and increased wound healing may be achieved in this way. However, reports are conflicting. Farid et al. [51] compared 49 eyes of 43 patients that underwent FSL-assisted zig-zag incision pattern PK vs 17 eyes of 14 patients that underwent conventional Barron suction trephination PK. They found that the greatest difference in astigmatism was observed at month 1 , followed by month 3 , when the average astigmatism was $4.5 \mathrm{D}$ in the conventional group vs $3.0 \mathrm{D}$ in the FSL group. On the other hand, Daniel et al. [53] found no significant difference in the refractive and visual outcomes after FSL-assisted PK compared with the guided trephine system keratoplasty. Most authors agree that FSL-assisted PK enables faster and more stable wound healing, allowing earlier complete suture removal than conventional PK. Nevertheless, the long-term refractive outcomes of the two techniques seem to be the same.

The use of the FSL in DALK allows the creation of accurate lamellar incisions and side cuts, facilitating the use of scissors to cut residual stroma from Descemet membrane and allowing a more secure wound closure and earlier suture removal [54].

\section{Corneal Cross-Linking}

The introduction of cornea cross-linking (CXL) in the late 1990s has significantly altered the management of keratoconic patients [55]. Recent studies report a significant reduction in the annual number of keratoplasties performed after CXL introduction [56, 57]. Most studies report a greater than $90 \%$ success rate in stabilization of keratoconus progression after $\mathrm{CXL}$ application [55].

In order to achieve a strengthening effect of corneal tissue and arrest keratoconus progression, the use of riboflavin (vitamin B2) is combined with ultraviolet A (UV-A) irradiation. Riboflavin plays the role of a photosensitizer in the photopolymerization process and when combined with UV-A irradiation increases the formation of intrafibrillar and interfibrillar carbonyl-based collagen covalent bonds through a molecular process that has still not been completely elucidated [58]. The effect of corneal cross-linking can be identified as a demarcation line observed during slit lamp examination and on anterior segment OCT. Many researchers believe that this demarcation line may act as an indicator of treatment depth and extent [59].

The standard Dresden protocol includes removal of the central $8-10 \mathrm{~mm}$ of the epithelium and application of a riboflavin solution (0.1\% riboflavin-5-phosphate and 20\% dextran $\mathrm{T}-500)$ to the corneal surface $30 \mathrm{~min}$ before irradiation and at 5-min intervals during the course of a 30-min exposure to 370-nm UV-A with an irradiance of $3 \mathrm{~mW} / \mathrm{cm}^{2}$ [60]. Several other protocols have been proposed that either maintain corneal epithelium or reduce exposure time as described below.

A number of studies have shown the beneficial results of CXL treatment in keratoconus in 
terms of visual acuity and topographic indices [21, 61-66]. A prospective clinical trial by Hersh et al. demonstrated improvement in visual acuity and maximum keratometry in patients with progressive keratoconus [21]. Vinciguerra et al. reported improvement in corneal and total wavefront aberrations as well as in uncorrected and corrected visual acuity after a 12-month follow-up following CXL [61]. Wittig-Silva et al. in their prospective, randomized trial reported statistically significant flattening of the steepest simulated keratometry value and improved visual acuity [63]. Interestingly, the effect of CXL treatment seems to extend beyond the first months of surgery with long-term follow-ups showing that corneal flattening continued for up to several years after treatment [64-66]. Preoperative factors that predict cross-linking efficacy have not been clearly established, though it seems that steep corneas with preoperative keratometry values greater than $58 \mathrm{D}$ and eccentric cone location have higher complication rates [67].

In terms of safety, proper application of the Dresden protocol in patients with corneal thickness of at least $400 \mu \mathrm{m}$ is considered a safe procedure [68]. It should be noted that corneal thickness measurements should be attained after epithelial removal and prior to application of riboflavin and UV-A light exposure in order to prevent UV toxicity to the endothelium. The use of hypoosmolar riboflavin is indicated in patients with borderline corneal thickness to swell the tissue, though there are some concerns about increased endothelial toxicity and reduced treatment efficacy. The majority of CXL complications arise from epithelial debridement; these include infection, sterile infiltrates, delayed re-epithelialization, corneal edema, and corneal haze [67].

\section{Plus}

Corneal cross-linking has proven over the years to be an effective and safe procedure in arresting keratoconus progression and increasing corneal resistance. However, visual rehabilitation for ectatic corneas also requires improvement in corneal curvature irregularity and reduction of the residual refractive error. Several adjuvant therapies in combination with CXL treatment have been proposed to not only arrest progression of keratoconus but also improve functional vision and delay or even prevent keratoplasty. The term "CXL plus," introduced in 2011 by Kymionis, refers to the several combined refractive procedures studied to enhance the CXL result [69].

CXL with topography-guided photorefractive keratectomy (PRK) was the first combined CXL treatment performed with the use of the excimer laser. Several variations of the technique have been proposed since, related to the timing of the two procedures (simultaneous or sequential), maximal recommended ablation depth, and the use of mitomycin C [70-73].

Regarding the sequence of the procedures, Kanellopoulos in his comparative study showed that same-day simultaneous topography-guided PRK followed by CXL is more effective than sequential CXL with delayed (6 months or more) PRK in the visual rehabilitation of ectasia [70]. The combination of treatments proposed by his team included sequential excimer laser epithelial debridement $(50 \mu \mathrm{m})$, partial topography-guided excimer laser stromal ablation, and high-fluence ultraviolet-A irradiation $\left(10 \mathrm{~mW} / \mathrm{cm}^{2}\right)$, accelerated $(10 \mathrm{~min}) \quad \mathrm{CXL}$ (Athens protocol) [71]. In a recent attempt to incorporate cyclorotation compensation in customized topography-guided treatments the sequence of procedures has been slightly altered with partial PRK being performed before the phototherapeutic keratectomy (PTK) step (enhanced Athens protocol) [72].

Regarding mitomycin $\mathrm{C}$ use following PRK, Kanellopoulos used mitomycin C $0.02 \%$ for $20 \mathrm{~s}$ [70]. On the other hand, Kymionis et al. avoided using mitomycin $\mathrm{C}$ based on the hypothesis that cross-linking of the ablated stroma offers the advantage of depopulating keratocytes in the anterior stroma, which could reduce the possibility of haze formation [73].

Anterior cornea remodeling and regression of anterior cornea irregularities with transepithelial phototherapeutic keratectomy (t-PTK) prior to CXL application has proven to be a valuable alternative to mechanical debridement of cornea epithelium. The Cretan protocol that 
first described the technique and several other subsequent studies showed improved visual and refractive outcomes [74, 75]. A potential explanation for the improved results is that performing t-PTK in eyes with keratoconus allows excimer laser ablation to remove corneal epithelium along with corneal stromal tissue on the apex of the cone, thus regularizing the anterior corneal surface and improving the efficacy of cross-linking [74].

The combination treatment of corneal cross-linking and ICRS offers not only stabilization of keratoconus but also improvement in visual and topographic outcomes in patients with keratoconus. There are several reports of promising results $[76,77]$ with the combined treatment, although some studies found that the synergistic effect did not prove superior to ICRS implantation alone. For example, Cakir et al. [78] and Ferenczy et al. [79] could not demonstrate superiority of combined ICRS and CXL treatment over ICRS treatment alone.

Cornea cross-linking can be performed before, during, or after ICRS implantation, but the ideal sequence and timing of this combination are still uncertain. Liu et al. retrospectively examined 41 eyes that were divided into three groups. Group 1 underwent sole ICRS implantation, group 2 underwent ICRS first followed by CXL immediately after, and group 3 underwent CXL first followed by ICRS long after. No significant differences were found among these three groups [80]. On the contrary, in a prospective randomized study, Coskunseven et al. showed that ICRS placement, followed by CXL, led to statistically superior keratometric, refractive, and visual outcomes than CXL followed by ring implantation [81].

Phakic intraocular lens (PIOL) implantation in addition to CXL is another alternative combined treatment of keratoconus performed to optimize the CXL outcome. Three types of PIOL are currently available for intraocular refractive correction: angle supported, iris fixated, and posterior chamber IOL. Although preliminary results are promising [82-85], long-term randomized comparative prospective studies with large cohorts are needed to evaluate the stability and potential complications of the procedure and to propose alternative treatments in cases of keratoconus progression and refractive change.

Treatments that combine cross-linking with corneal ring segments and PRK have also shown promising results. Combined treatments have shown significantly improved uncorrected distance visual acuity, corrected distance visual acuity, and central keratometry value, and consequently visual function, in patients with moderate keratoconus [86-91]. Long-term follow-up will be important in these patients to determine the stability of visual outcomes.

\section{Accelerated Cross-Linking}

Given the favorable ectasia-stabilizing results with cornea cross-linking therapy, clinical efforts are aimed at optimizing the procedure's treatment time, intra- and postoperative comfort, and efficacy.

For example, accelerated CXL using higher irradiance UV-A to shorten the amount of time necessary to deliver the equivalent total energy dose is a new alternative [92, 93]. This technique is based on the Bunsen-Roscoe law of photochemical reciprocity. That is, the same photochemical effect can be achieved by delivering a similar total energy over a shorter period of time.

Several recent in vivo studies using different protocols showed the procedure to be safe and effective in stopping ectasia progression (Table 4). Yıldırım et al. compared 74 eyes treated with intended UV-A radiance of $5.4 \mathrm{~J} / \mathrm{cm}^{2}$ and 72 eyes treated with radiance of $7.2 \mathrm{~J} / \mathrm{cm}^{2}$ and found similar refractive and topographic outcomes in the two groups [94]. Alnawaiseh et al. used an $18 \mathrm{~mW} / \mathrm{cm}^{2}$ for a 5-min protocol on 28 eyes with mean follow-up time of 21.7 months reporting effective halting of keratoconus progression [95]. Tomita et al. examined two different riboflavin application times (15 and $30 \mathrm{~min}$ ) [96]. In this study, both protocols had similar outcomes relative to conventional CXL. Regarding the safety and the recovery time following the procedure, both Ozgurhan et al. and Hashemian et al. found less sub-basal nerve disruption using the accelerated protocols $[97,98]$. 
Table 4 Comparative randomized control trials between accelerated cross-linking protocols vs the Dresden protocol

\begin{tabular}{|c|c|c|c|}
\hline Author & Number of eyes and protocol used & $\begin{array}{l}\text { Follow-up } \\
\text { (months) }\end{array}$ & Outcomes \\
\hline $\begin{array}{l}\text { Hashemi } \\
\text { et al. [92] }\end{array}$ & $\begin{array}{l}31 \text { eyes } 18 \mathrm{~mW} / \mathrm{cm}^{2} 5 \mathrm{~min} \text { vs } 31 \text { eyes } \\
\text { Dresden protocol }\end{array}$ & 18 & $\begin{array}{l}\text { Comparable outcomes and safety profile between } \\
\text { methods }\end{array}$ \\
\hline Sherif [93] & $\begin{array}{l}14 \text { eyes } 30 \mathrm{~mW} / \mathrm{cm}^{2} \text { for } 4 \mathrm{~min} 20 \mathrm{~s} \text { vs } 11 \\
\text { eyes Dresden protocol }\end{array}$ & 12 & $\begin{array}{l}\text { Both groups had comparable visual acuity } \\
\text { improvement }\end{array}$ \\
\hline $\begin{array}{l}\mathrm{Ng} \text { et al. } \\
\quad[99]\end{array}$ & $\begin{array}{l}12 \text { eyes } 9 \mathrm{~mW} / \mathrm{cm}^{2} \text { for } 10 \mathrm{~min} \text { vs } 14 \\
\text { eyes Dresden protocol }\end{array}$ & $13.9 \pm 6.3$ & $\begin{array}{l}\text { Both procedures stopped keratoconus progression. } \\
\text { Conventional group presented greater corneal } \\
\text { flattening, which correlated with a deeper corneal } \\
\text { stromal demarcation line }\end{array}$ \\
\hline $\begin{array}{l}\text { Razmjoo } \\
\text { et al. } \\
{[100]}\end{array}$ & $\begin{array}{l}20 \text { eyes } 18 \mathrm{~mW} / \mathrm{cm}^{2} \text { for } 5 \mathrm{~min} \text { vs } 20 \text { eyes } \\
\text { Dresden protocol }\end{array}$ & 6 & $\begin{array}{l}\text { No significant difference in visual acuity, refractive } \\
\text { criteria, and topographic criteria }\end{array}$ \\
\hline $\begin{array}{l}\text { Cinar et al. } \\
\text { [101] }\end{array}$ & $\begin{array}{l}13 \text { eyes } 9 \mathrm{~mW} / \mathrm{cm}^{2} \text { for } 10 \mathrm{~min} \text { vs } 13 \text { eyes } \\
\text { Dresden protocol }\end{array}$ & 6 & $\begin{array}{l}\text { No statistically significant difference in visual and } \\
\text { refractive results between the two groups }\end{array}$ \\
\hline $\begin{array}{l}\text { Choi et al. } \\
\text { [102] }\end{array}$ & $\begin{array}{l}13 \text { eyes } 30 \mathrm{~mW} / \mathrm{cm}^{2} \text { for } 3 \mathrm{~min} 40 \mathrm{~s} \text { vs } 15 \\
\text { eyes Dresden protocol }\end{array}$ & 6 & $\begin{array}{l}\text { A-CXL showed a smaller topographic flattening } \\
\text { effect than did the conventional Dresden protocol }\end{array}$ \\
\hline $\begin{array}{l}\text { Tomita } \\
\text { et al. [96] }\end{array}$ & $\begin{array}{l}30 \text { eyes had } 15 \mathrm{~min} \text { riboflavin pre-soak } \\
\text { and } 30 \mathrm{~mW} / \mathrm{cm}^{2} 3 \mathrm{~min} \text { vs } 18 \text { eyes } \\
\text { Dresden protocol }\end{array}$ & 12 & $\begin{array}{l}\text { Both procedures were safe and efficient in halting } \\
\text { keratoconus progression }\end{array}$ \\
\hline $\begin{array}{l}\text { Shetty et al. } \\
\qquad[103]\end{array}$ & $\begin{array}{l}36 \text { eyes, } 3 \mathrm{~mW} / \mathrm{cm}^{2} \text { for } 30 \mathrm{~min} \\
36 \text { eyes, } 9 \mathrm{~mW} / \mathrm{cm}^{2} \text { for } 10 \mathrm{~min} \\
33 \text { eyes, } 18 \mathrm{~mW} / \mathrm{cm}^{2} \text { for } 5 \mathrm{~min} \\
33 \text { eyes, } 30 \mathrm{~mW} / \mathrm{cm}^{2} \text { for } 3 \mathrm{~min}\end{array}$ & 12 & $\begin{array}{l}\text { Conventional CXL and accelerated CXL with } \\
\text { irradiations of } 9 \text { and } 18 \mathrm{~mW} / \mathrm{cm}^{2} \text { showed better } \\
\text { visual, refractive, and tomographic results }\end{array}$ \\
\hline $\begin{array}{l}\text { Sadoughi } \\
\text { et al. } \\
\text { [104] }\end{array}$ & $\begin{array}{l}12 \text { eyes } 9 \mathrm{~mW} / \mathrm{cm}^{2} \text { for } 10 \mathrm{~min} \\
12 \text { eyes Dresden protocol }\end{array}$ & 12 & $\begin{array}{l}\text { Similar refractive, visual, keratometric, and } \\
\text { aberrometric results and less adverse effects on the } \\
\text { corneal thickness and endothelial cells on both } \\
\text { groups }\end{array}$ \\
\hline $\begin{array}{l}\text { Cummings } \\
\text { et al. } \\
{[105]}\end{array}$ & $\begin{array}{l}66 \text { eyes, Dresden protocol } \\
36 \text { eyes, } 9 \mathrm{~mW} / \mathrm{cm}^{2} \text { for } 10 \mathrm{~min}\end{array}$ & 12 & Better flattening effect in accelerated group \\
\hline
\end{tabular}

$C X L$ cornea cross-linking, $A-C X L$ accelerated cornea cross-linking

Some investigators have observed a shallower postoperative demarcation line, indicating reduced riboflavin penetration and CXL treatment depth [106]. However, Kymionis et al. using modified accelerated protocols $\left(18 \mathrm{~mW} / \mathrm{cm}^{2}\right.$ for $7 \mathrm{~min}$ and $9 \mathrm{~mW} / \mathrm{cm}^{2}$ for $14 \mathrm{~min}$ ) found no difference in the depth of the demarcation line in comparison to standard CXL [107]. Despite the controversies regarding the efficacy of accelerated cross-linking, the technique has been gaining popularity over the last few years. The protocol which will provide optimum results is still under investigation. 


\section{Keratoconus Treatment Algorithm}

To date, there are no specific guidelines on keratoconus management. Several treatment modalities are available and the selection of the optimum therapy depends on the patient's cornea parameters and the rate of keratoconus progression.

In patients with advanced forms of keratoconus (stage IV according to Amsler-Krumeich classification), the indicated treatment methods are deep anterior lamellar keratoplasty or penetrating keratoplasty [41, 42]. As previously mentioned, several parameters such as corneal thickness, corneal steepness, endothelial cells dysfunction, crystalline lens opacities, patient's age, and corneal scarring need to be considered before selection of the optimal surgical procedure [42].

In less advanced keratoconic cases (corneal thickness above $400 \mu \mathrm{m}$ with transparent cornea) (stage I, II, III), management of the patient depends on four factors: the age, the stability of the disease, the spectacles or contact lens tolerance, and the degree of corneal irregularity. In stable cases, if the visual function with spectacles or contact lenses is satisfactory, there is no need for surgical intervention and the patients should be advised to avoid eye rubbing and topical antihistaminic agents could be prescribed (Fig. 1). Patients should undergo thorough ophthalmological evaluation (including corneal topography) every 6 months, especially the young patients in whom the disease is characterized by more rapid progression [4].

On the contrary, in stable keratoconic cases with contact lens or spectacle intolerance (due to irregular astigmatism, anisometropia, or high refractive error), the optimal treatment modality is the combination of CXL with transepithelial phototherapeutic keratectomy (t-PTK) and/or topo-guided photorefractive keratectomy in order to regularize the corneal surface without destabilizing the disease status (Fig. 1) $[70,74]$. Alternatively, corneal irregularity may be surgically improved by insertion of intrastromal corneal ring segments (in patients with irregular astigmatism and corneal thickness not suitable for laser ablation), while in older patients with stable disease, high refractive error, and irregular astigmatism, phakic IOL should be considered [33, 108]. Pseudophakic toric intraocular lens implantation is a satisfactory option in eyes with stable, mild to

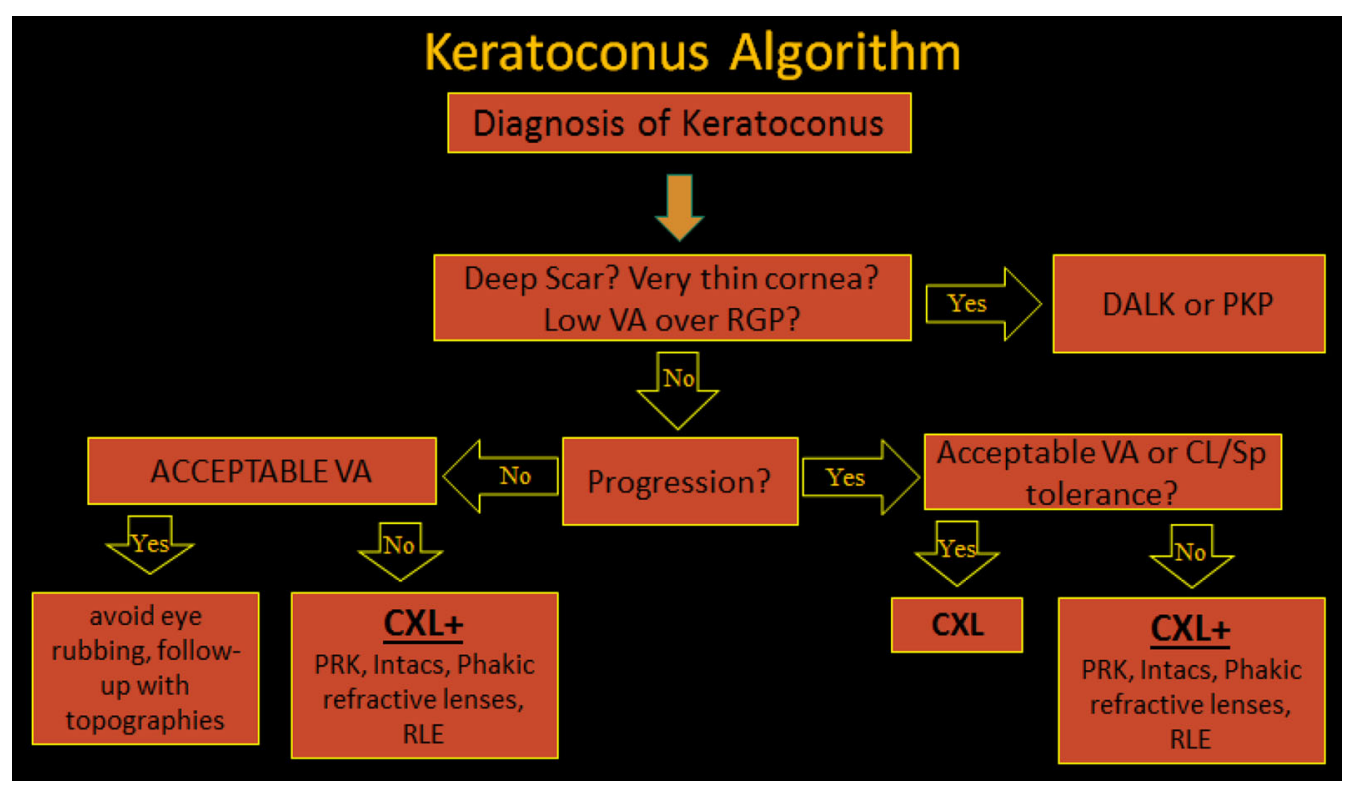

Fig. 1 Keratoconus treatment algorithm. $V A$ visual acuity, $R G P$ rigid gas-permeable lens, $D A L K$ deep anterior lamellar keratoplasty, $P K$ penetrating keratoplasty, $C L$ contact lens, $S p$ spectacle, $C X L$ cornea cross-linking, $P R K$ photorefractive keratectomy, $R L E$ refractive lens exchange 
moderate keratoconus, and cataract [109], while in patients older than 50 , clear lens surgery with posterior chamber lens implantation is an effective alternative (Fig. 1).

In cases where progression of the disease is established topographically with or without corneal thinning, CXL treatment is proposed for the stabilization of the ectatic disease (Fig. 1). In patients with increased corneal irregularity and contact lens or spectacle intolerance a combination of CXL with additional refractive procedures could be considered in order to provide both corneal stability and functional vision. More specifically, CXL may be combined with t-PTK and/or PRK wherever the corneal irregularity may be improved with laser ablation techniques, provided that after ablation and before CXL, the corneal thickness remains over $400 \mu \mathrm{m}$ [70, 74]. Alternatively, in patients who do not meet the safety limits regarding corneal thickness for laser procedure, ICRS could be used to reshape the cornea and reduce the refractive error followed by CXL in order to achieve corneal stability [81]. In cases with high refractive errors (myopia and regular astigmatism), performance of CXL may be followed by insertion of Phakic IOL with an interval time of 6-12 months (Fig. 1) [83].

\section{FUTURE OF KERATOCONUS TREATMENT}

All treatment options discussed earlier have proven efficient and safe in the management of keratoconus. Latest technological advancements have created a new trend towards less invasive procedures. The ultimate goal would be sutureless procedures and less intra- and postoperative complications that could achieve permanent corneal flattening and visual rehabilitation.

\section{Pulse CXL}

One hypothesis explaining the shallower effect observed with accelerated cross-linking protocols is the higher oxygen consumption leading to oxygen depletion. One way to increase oxygen concentration in the cornea during accelerated CXL is to deliver pulsed irradiation to allow oxygen to diffuse into the stroma during non-irradiation intervals. As a result, on-off pattern protocols may have the potential to increase the corneal stiffening effect obtained with the same UV-A dose, and may potentially lead to a reduction in procedure time by increasing the treatment efficacy of high irradiance CXL. Preliminary results by Peyman et al. and Mazzotta et al. with pulsed irradiation are promising, indicating safety equivalent to the continuous UV exposure protocols, albeit with greater demarcation line depth [110, 111]. Park et al. recently showed a considerably deeper effect in the cornea stroma using accelerated pulsed UV-A than continuous UV-A [112].

\section{Epi-on Cross-Linking}

In an attempt to avoid standard CXL treatment complications and postoperative pain, several methods have been introduced to enhance riboflavin penetration through an intact epithelium. Finding an effective cross-linking technique with retention of the epithelium is the subject of many studies. Riboflavin formulations with added corneal-enhancing compounds like benzalkonium chloride, ethylenediaminetetraacetic acid, and tetracaine can improve riboflavin diffusion despite epithelial presence [113-115]. Intrastromal channels and flaps as alternative routes have also been proposed [116, 117]. Significant controversial results have been reported with the various transepithelial techniques.

Iontophoresis-assisted corneal cross-linking is a non-invasive approach in which a low-intensity electric current enhances the penetration of riboflavin into the stroma and facilitates more precise, homogeneous diffusion of the ionized molecule through the epithelium [118]. Ex vivo studies on rabbit and human cadaveric corneas showed that iontophoresis transepithelial cross-linking induced an increase in the biomechanical resistance of human cornea comparable to that obtained with the standard cross-linking procedure. 
Clinical studies have shown an improvement in BCVA, and no changes in central corneal thickness and endothelial cell density. However, recent studies indicate that while iontophoresis-assisted corneal cross-linking successfully halts keratoconus progression, standard CXL seems more effective with deeper stromal cornea collagen cross-links and better average topographic results $[119,120]$. Moreover, the demarcation line found after iontophoresis is fainter and less deep than that found after traditional epithelium-off techniques [121].

\section{Using Topography-Guided UV-A Energy Emission}

In addition to varying the depth of cross-linking by modifying parameters like UV-A irradiance, total energy dose, and UV-A frequency, the lateral distribution of cross-link formation in the cornea may be better controlled through the use of customized UV-A illumination patterns that would allow targeted stiffening of the weakest regions of the cornea rather than the conventional approach of uniformly stiffening the entire central cornea. A number of ongoing studies are evaluating the efficacy of the procedures. Mazzotta et al. retrospectively examined 21 eyes that underwent accelerated cross-linking using a UV-A exposure with an energy release varying from 7.2 up to $15 \mathrm{~J} /$ $\mathrm{cm}^{2}$, according to the topographic corneal curvature with favorable 1-year results [122]. Nordström et al. reported similar promising results in their prospective clinical trial [123].

\section{Bowman Layer Transplantation}

The first use of Bowman layer transplantation (BL) was to manage persistent subepithelial haze after excimer laser surface ablation [124]. Melles and his team came up with the idea to use BL transplantation to halt keratoconus progression [125]. The rationale behind Bowman transplantation is that since fragmentation of the Bowman layer is a pathognomic feature in advanced keratoconus, a partial restoration of the anatomy might be achieved through a midstromal implant of an isolated Bowman layer graft to remodel corneal curvature. At the same time, stabilization of the ectasia may be obtained by the Bowman layer splint and through the wound-healing reaction between the host stroma and the Bowman layer graft. Parker et al. performed the technique in 22 eyes of 19 patients with advanced keratoconus. The authors reported a decrease on average maximum keratometry at 1 month after surgery which remained stable thereafter, and an improvement in mean BSCVA, with no change in endothelial cell density. At 5-year follow-up, Bowman layer transplantation stabilized disease in $90 \%$ of 22 eyes with advanced keratoconus. The authors concluded that given the low risk for complications, the procedure is a safe and effective method of stabilizing keratoconus and may be performed to postpone penetrating or deep anterior lamellar keratoplasty [126].

\section{CONCLUSION}

Keratoconus management has significantly changed over the last few years. Cornea clinicians nowadays can perform a number of treatment modalities that can halt disease progression and alter cornea shape in a safe and effective way, thus providing optimum visual results in keratoconus patients. Future developments may further improve the safety and efficacy of these therapies. More studies are needed to provide clinical data to prove their short- and long-term effectiveness.

\section{ACKNOWLEDGEMENTS}

No funding or sponsorship was received for this study or publication of this review. All named authors meet the International Committee of Medical Journal Editors (ICMJE) criteria for authorship for this manuscript, take responsibility for the integrity of the work as a whole, and have given final approval to the version to be published.

Disclosures. Konstantinos D. Andreanos, Kate Hashemi, Myrsini Petrelli, Konstantinos 
Droutsas, Ilias Georgalas, and George D Kymionis have nothing to disclose.

Compliance with Ethics Guidelines. This article is based on previously conducted studies and does not involve any new studies of human or animal subjects performed by any of the authors.

Open Access. This article is distributed under the terms of the Creative Commons Attribution-NonCommercial 4.0 International License (http://creativecommons.org/licenses/ by-nc/4.0/), which permits any noncommercial use, distribution, and reproduction in any medium, provided you give appropriate credit to the original author(s) and the source, provide a link to the Creative Commons license, and indicate if changes were made.

\section{REFERENCES}

1. Rabinowitz YS. Keratoconus. Surv Ophthalmol. 1998;42:297-319.

2. Grzybowski A, McGhee CN. The early history of keratoconus prior to Nottingham's landmark 1854 treatise on conical cornea: a review. Clin Exp Optom. 2013;96(2):140-5.

3. Gokul A, Patel DV, McGhee CN. Dr John Nottingham's 1854 landmark treatise on conical cornea considered in the context of the current knowledge of keratoconus. Cornea. 2016;35(5):673-8.

4. Gomes JA, et al. Global consensus on keratoconus and ectatic diseases. Cornea. 2015;34(4):359-69.

5. Millodot M, Ortenberg I, Lahav-Yacouel K, Behrman S. Effect of ageing on keratoconic corneas. J Optom. 2016;9(2):72-7.

6. Gorskova EN, Sevostianov EN. Epidemiology of keratoconus in the Urals. Vestn Oftalmol. 1998;114(4):38-40.

7. Jonas JB, Nangia V, Matin A, Kulkarni M, Bhojwani K. Prevalence and associations of keratoconus in rural Maharashtra in Central India: the central India eye and medical study. Am J Ophthalmol. 2009;148(5):760-5.

8. Kennedy RH, Bourne WM, Dyer JA. A 48-year clinical and epidemiologic study of keratoconus. Am J Ophthalmol. 1986;101:267-73.
9. Godefrooij DA, de Wit GA, Uiterwaal CS, Imhof SM, Wisse RP. Age-specific incidence and prevalence of keratoconus: a nationwide registration study. Am J Ophthalmol. 2017;175:169-72.

10. Woodward MA, Blachley TS, Stein JD. The Association between sociodemographic factors, common systemic diseases, and keratoconus: an analysis of a nationwide heath care claims database. Ophthalmology. 2016;123(3):457-65.

11. Zadnik K, Barr JT, Edrington TB, et al. Baseline findings in the Collaborative Longitudinal Evaluation of Keratoconus (CLEK) study. Invest Ophthalmol Vis Sci. 1998;39(13):2537-46.

12. Maharana PK, Sharma N, Vajpayee RB. Acute corneal hydrops in keratoconus. Indian J Ophthalmol. 2013;61(8):461-4.

13. Kim SW, Sun HJ, Chang JH, Kim EK. Anterior segment measurements using Pentacam and Orbscan II 1 to 5 years after refractive surgery. J Refract Surg. 2009;25:1091-7.

14. Belin MW, Ambrósio R. Scheimpflug imaging for keratoconus and ectatic disease. Indian J Ophthalmol. 2013;61:401-6.

15. Holladay JT. Keratoconus detection using corneal topography. J Refract Surg. 2009;25:S958-62.

16. Kanellopoulos AJ, Asimellis G. OCT-derived comparison of corneal thickness distribution and asymmetry differences between normal and keratoconic eyes. Cornea. 2014;33:1274-81.

17. Kanellopoulos AJ, Asimellis G. OCT corneal epithelial topographic asymmetry as a sensitive diagnostic tool for early and advancing keratoconus. Clin Ophthalmol. 2014;8:2277-87.

18. Randleman JB, Russell B, Ward MA, et al. Risk factors and prognosis for corneal ectasia after LASIK. Ophthalmology. 2003;110:267-75.

19. Kanellopoulos AJ, Asimellis G. Revisiting keratoconus diagnosis and progression classification based on evaluation of corneal asymmetry indices, derived from Scheimpflug imaging in keratoconic and suspect cases. Clin Ophthalmol. 2013;7:1539-48.

20. Labiris G, Kozobolis V. A proposed biomechanical scale for the diagnosis of corneal ectatic disorders. Eur J Ophthalmol. 2015;25:3-4.

21. Hersh PS, Greenstein SA, Fry KL. Corneal collagen crosslinking for keratoconus and corneal ectasia: one-year results. J Cataract Refract Surg. 2011;37(1):149-60. 
22. Barnett M, Mannis MJ. Contact lenses in the management of keratoconus. Cornea. 2011;30:1510-6.

23. Katsoulos C, Karageorgiadis L, Vasileiou N, Mousafeiropoulos T, Asimellis G. Customized hydrogel contact lenses for keratoconus incorporating correction for vertical coma aberration. Ophthalmic Physiol Opt. 2009;29:321-9.

24. Pilskalns B, Fink BA, Hill RM. Oxygen demands with hybrid contact lenses. Optom Vis Sci. 2007;84:334-42.

25. Rathi VM, Mandathara PS, Dumpati S. Contact lens in keratoconus. Indian J Ophthalmol. 2013;61(8):410-5.

26. Picot C, Gauthier AS, Campolmi N, Delbosc B. Quality of life in patients wearing scleral lenses. J Fr Ophtalmol. 2015;38(7):615-9.

27. Bandlitz S, Bäumer J, Conrad U, Wolffsohn J. Scleral topography analysed by optical coherence tomography. Cont Lens Anterior Eye. 2017;40(4):242-7.

28. Heikal MA, Abdelshafy M, Soliman TT, Hamed AM. Refractive and visual outcomes after Keraring intrastromal corneal ring segment implantation for keratoconus assisted by femtosecond laser at 6 months follow-up. Clin Ophthalmol. 2016;23(11):81-6.

29. Shetty R, Kurian M, Anand D, Mhaske P, Narayana $\mathrm{KM}$, Shetty BK. Intacs in advanced keratoconus. Cornea. 2008;27:1022-9.

30. Shabayek MH, Alió JL. Intrastromal corneal ring segment implantation by femtosecond laser for keratoconus correction. Ophthalmology. 2007;114(9):1643-52.

31. Alió JL, Artola A, Hassanein A, Haroun H, Galal A. One or 2 Intacs segments for the correction of keratoconus. J Cataract Refract Surg. 2005;31:943-53.

32. Siganos D, Ferrara P, Chatzinikolas K, Bessis N, Papastergiou G. Ferrara intrastromal corneal rings for the correction of keratoconus. J Cataract Refract Surg. 2002;28:1947-51.

33. Kanellopoulos AJ, Pe LH, Perry HD, Donnenfeld ED. Modified intracorneal ring segment implantations (INTACS) for the management of moderate to advanced keratoconus: efficacy and complications. Cornea. 2006;25:29-33.

34. Vega-Estrada A, Alio JL, Brenner LF, et al. Outcome analysis of intracorneal ring segments for the treatment of keratoconus based on visual, refractive, and aberrometric impairment. Am J Ophthalmol. 2013;155(3):575-84.
35. Vega-Estrada A, Alió JL, Plaza-Puche AB. Keratoconus progression after intrastromal corneal ring segment implantation in young patients: five-year follow-up. J Cataract Refract Surg. 2015;41(6):1145-52.

36. Pramanik S, Musch DC, Sutphin JE, Farjo AA. Extended long-term outcomes of penetrating keratoplasty for keratoconus. Ophthalmology. 2006;113:1633-8.

37. Sarnicola V, Toro P, Gentile D, Hannush SB. Descemetic DALK and predescemetic DALK: outcomes in 236 cases of keratoconus. Cornea. 2010;29:53-9.

38. Parker JS, van Dijk K, Melles GR. Treatment options for advanced keratoconus: a review. Surv Ophthalmol. 2015;60:459-80.

39. Lu Y, Grisolia AB, Ge YR, et al. Comparison of femtosecond laser-assisted descemetic and predescemetic lamellar keratoplasty for keratoconus. Indian J Ophthalmol. 2017;65(1):19-23.

40. Liu H, Chen Y, Wang P, et al. Efficacy and safety of deep anterior lamellar keratoplasty vs. penetrating keratoplasty for keratoconus: a meta-analysis. PLoS One. 2015;10:1.

41. Jones MN, Armitage WJ, Ayliffe W, et al. Penetrating and deep anterior lamellar keratoplasty for keratoconus: a comparison of graft outcomes in the United Kingdom. Invest Ophthalmol Vis Sci. 2009;50:5625-9.

42. Henein C, Nanavaty MA. Systematic review comparing penetrating keratoplasty and deep anterior lamellar keratoplasty for management of keratoconus. Cont Lens Anterior Eye. 2017;40(1):3-14.

43. Panda A, Vanathi M, Kumar A, Dash Y, Priya S. Corneal graft rejection. Surv Ophthalmol. 2007;52(4):375-96.

44. Watson SL, Tuft SJ, Dart JK. Patterns of rejection after deep lamellar keratoplasty. Ophthalmology. 2006;113(4):556-60.

45. Borderie VM, Sandali O, Bullet J, Gaujoux T, Touzeau $\mathrm{O}$, Laroche L. Long-term results of deep anterior lamellar versus penetrating keratoplasty. Ophthalmology. 2012;119(2):249-55.

46. Den S, Shimmura S, Tsubota K, Shimazaki J. Impact of the descemet membrane perforation on surgical outcomes after deep lamellar keratoplasty. Am J Ophthalmol. 2007;143(5):750-4.

47. Melles GR, Rietveldt FJ, Beekuis WH, Binder PS. A technique to visualize corneal incision and lamellar dissection depth during surgery. Cornea. 1999;18:80-6. 
48. Anwar M, Teichmann KD. Big-bubble technique to bare Descemet's membrane in anterior lamellar keratoplasty. J Cataract Refract Surg. 2002;28(3):398-403.

49. Diakonis VF, Yoo SH, Hernandez V, et al. Femtosecond-assisted big bubble: a feasibility study. Cornea. 2016;35(12):1668-71.

50. Siebelmann S, Steven P, Cursiefen C. Intraoperative optical coherence tomography in deep anterior lamellar keratoplasty. Klin Monbl Augenheilkd. 2016;233(6):717-21.

51. Farid M, Steinert RF, Gaster RN, Chamberlain W, Lin A. Comparison of penetrating keratoplasty performed with a femtosecond laser zig-zag incision versus conventional blade trephination. Ophthalmology. 2009;116(9):1638-43.

52. Fung SS, Aiello F, Maurino V. Outcomes of femtosecond laser-assisted mushroom-configuration keratoplasty in advanced keratoconus. Eye (Lond). 2016;30(4):553-61.

53. Daniel MC, Böhringer D, Maier $P$, Eberwein $P$, Birnbaum F, Reinhard T. Comparison of long-term outcomes of femtosecond laser-assisted keratoplasty with conventional keratoplasty. Cornea. 2016;35(3):293-8.

54. Li S, Wang T, Bian J, Wang F, Han S, Shi W. Precisely controlled side cut in femtosecond laser-assisted deep lamellar keratoplasty for advanced keratoconus. Cornea. 2016;35(10):1289-94.

55. Wollensak G. Corneal collagen crosslinking: new horizons. Expert Rev Ophthalmol. 2010;5:201-15.

56. Sandvik GF, Thorsrud A, Raen M, Ostern AE, Sathre $\mathrm{M}$, Drolsum L. Does corneal collagen cross-linking reduce the need for keratoplasties in patients with keratoconus? Cornea. 2015;34(9):991-5.

57. Godefrooij DA, Gans R, Imhof SM, Wisse RP. Nationwide reduction in the number of corneal transplantations for keratoconus following the implementation of cross-linking. Acta Ophthalmol. 2016;94(7):675-8.

58. Zhang Y, Conrad AH, Conrad GW. Effects of ultraviolet-A and riboflavin on the interaction of collagen and proteoglycans during corneal cross-linking. J Biol Chem. 2011;286(15):13011-22.

59. Yam JC, Chan CW, Cheng AC. Corneal collagen cross-linking demarcation line depth assessed by Visante OCT after CXL for keratoconus and corneal ectasia. J Refract Surg. 2012;28(7):475-81.

60. Wollensak G, Spoerl E, Seiler T. Riboflavin/ultraviolet-a-induced collagen crosslinking for the treatment of keratoconus. Am J Ophthalmol. 2003;135(5):620-7.

61. Vinciguerra P, Albè E, Trazza S, et al. Refractive, topographic, tomographic, and aberrometric analysis of keratoconic eyes undergoing corneal cross-linking. Ophthalmology. 2009;116:369-78.

62. Coskunseven E, Jankov MR II, Hafezi F. Contralateral eye study of corneal collagen cross-linking with riboflavin and UVA irradiation in patients with keratoconus. J Refract Surg. 2009;25:371-6.

63. Wittig-Silva C, Whiting M, Lamoureux E, Lindsay RG, Sullivan LJ, Snibson GR. A randomized controlled trial of corneal collagen cross-linking in progressive keratoconus: preliminary results. J Refract Surg. 2008;24(7):S720-5.

64. Hashemi H, Seyedian MA, Miraftab M, Fotouhi A, Asgari S. Corneal collagen cross-linking with riboflavin and ultraviolet a irradiation for keratoconus: long-term results. Ophthalmology. 2013;120:1515-20.

65. Raiskup F, Theuring A, Pillunat LE, Spoerl E. Corneal collagen crosslinking with riboflavin and ultraviolet-A light in progressive keratoconus: tenyear results. J Cataract Refract Surg. 2015;41(1):41-6.

66. Caporossi A, Mazzotta C, Baiocchi S, Caporossi T. Long-term results of riboflavin ultraviolet a corneal collagen cross-linking for keratoconus in Italy: the Siena eye cross study. Am J Ophthalmol. 2010;149(4):585-93.

67. Koller T, Mrochen M, Seiler T. Complication and failure rates after corneal crosslinking. J Cataract Refract Surg. 2009;35(8):1358-62.

68. Kymionis GD, Portaliou DM, Diakonis VF, Kounis GA, Panagopoulou SI, Grentzelos MA. Corneal collagen cross-linking with riboflavin and ultraviolet-A irradiation in patients with thin corneas. Am J Ophthalmol. 2012;153(1):24-8.

69. Kymionis GD. Corneal collagen cross linking-PLUS. Open Ophthalmol J. 2011;5:10.

70. Kanellopoulos AJ. Comparison of sequential vs same-day simultaneous collagen cross-linking and topography-guided PRK for treatment of keratoconus. J Refract Surg. 2009;25:S812-8.

71. Kanellopoulos AJ, Binder PS. Management of corneal ectasia after LASIK with combined, same-day, topography-guided partial transepithelial PRK and collagen cross-linking: the Athens protocol. J Refract Surg. 2011;27(5):323-31.

72. Kanellopoulos AJ, Asimellis G. Novel placido-derived topography-guided excimer corneal 
normalization with cyclorotation adjustment: enhanced Athens protocol for keratoconus. J Refract Surg. 2015;31(11):768-73.

73. Kymionis GD, Portaliou DM, Kounis GA, et al. Simultaneous topography-guided photorefractive keratectomy followed by corneal collagen cross-linking for keratoconus. Am J Ophthalmol. 2011;152:748-55.

74. Kymionis GD, Grentzelos MA, Kankariya VP, Pallikaris IG. Combined transepithelial phototherapeutic keratectomy and corneal collagen crosslinking for ectatic disorders: Cretan protocol. J Cataract Refract Surg. 2013;39:1939.

75. Kapasi M, Baath J, Mintsioulis G, Jackson WB, Baig K. Phototherapeutic keratectomy versus mechanical epithelial removal followed by corneal collagen crosslinking for keratoconus. Can J Ophthalmol. 2012;47(4):344-7.

76. Alió JL, Toffaha BT, Piñero DP, Klonowski P, Javaloy J. Crosslinking in progressive keratoconus using an epithelial debridement or intrastromal pocket technique after previous corneal ring segment implantation. J Refract Surg. 2011;27:737-43.

77. Vicente LL, Boxer Wachler BS. Factors that correlate with improvement in vision after combined Intacs and trans-epithelial corneal crosslinking. Br J Ophthalmol. 2010;94(12):1597-601.

78. Cakir H, Pekel G, Perente I, Genç S. Comparison of intrastromal corneal ring segment implantation only and in combination with collagen crosslinking for keratoconus. Eur J Ophthalmol. 2013;23(5):629-34.

79. Ferenczy PA, Dalcegio M, Koehler M, Pereira TS, Moreira H, Luciane Bugmann M. Femtosecond-assisted intrastromal corneal ring implantation for keratoconus treatment: a comparison with crosslinking combination. Arq Bras Oftalmol. 2015;78(2):76-81.

80. Liu XL, Li PH, Fournie P, Malecaze F. Investigation of the efficiency of intrastromal ring segments with cross-linking using different sequence and timing for keratoconus. Int J Ophthalmol. 2015;8(4):703-8.

81. Coskunseven E, Jankov MR 2nd, Hafezi F, Atun S, Arslan E, Kymionis GD. Effect of treatment sequence in combined intrastromal corneal rings and corneal collagen crosslinking for keratoconus. J Cataract Refract Surg. 2009;35(12):2084-91.

82. Antonios R, Dirani A, Fadlallah A, et al. Safety and visual outcome of Visian toric ICL implantation after corneal collagen cross-linking in keratoconus: up to 2 years of follow-up. J Ophthalmol. 2015;2015:514834. doi:10.1155/2015/514834.
83. Kymionis GD, Grentzelos MA, Karavitaki AE, Zotta $\mathrm{P}$, Yoo SH, Pallikaris IG. Combined corneal collagen cross-linking and posterior chamber toric implantable collamer lens implantation for keratoconus. Ophthalmic Surg Lasers Imaging. 2011;42:e22-5.

84. Fadlallah A, Dirani A, El Rami H, Cherfane G, Jarade E. Safety and visual outcome of Visian toric ICL implantation after corneal collagen cross-linking in keratoconus. J Refract Surg. 2013;29:84-9.

85. Shafik Shaheen M, El-Kateb M, El-Samadouny MA, Zaghloul H. Evaluation of atoric implantable collamer lens after corneal collagen crosslinking in treatment of early-stage keratoconus: 3-year follow-up. Cornea. 2014;33(5):475-80.

86. Kymionis GD, Grentzelos MA, Portaliou DM, et al. Photorefractive keratectomy followed by same-day corneal collagen cross-linking after intrastromal corneal ring segment implantation for pellucid marginal degeneration. J Cataract Refract Surg. 2010;36:1783-5.

87. Kanellopoulos AJ, Skouteris VS. Secondary ectasia due to forceps injury at childbirth: management with combined topography-guided partial PRK and collagen cross-linking (Athens protocol) and subsequent phakic IOL implantation. J Refract Surg. 2011;27:635-6.

88. Iovieno A, Légaré ME, Rootman DB, Yeung SN, Kim $\mathrm{P}$, Rootman DS. Intracorneal ring segments implantation followed by same-day photorefractive keratectomy and corneal collagen cross-linking in keratoconus. J Refract Surg. 2011;27:915-8.

89. Kremer I, Aizenman I, Lichter H, Shayer S, Levinger S. Simultaneous wavefront-guided photorefractive keratectomy and corneal collagen crosslinking after intrastromal corneal ring segment implantation for keratoconus. J Cataract Refract Surg. 2012;38:1802-7.

90. Coskunseven E, Jankov MR II, Grentzelos MA, Plaka AD, Limnopoulou AN, Kymionis GD. Topography-guided transepithelial PRK after intracorneal ring segments implantation and corneal collagen CXL in a three-step procedure for keratoconus. J Refract Surg. 2013;29:54-8.

91. Coskunseven E, Sharma DP, Jankov MR II, Kymionis GD, Richoz O, Hafezi F. Collagen copolymer toric phakic intraocular lens for residual myopic astigmatism after intrastromal corneal ring segment implantation and corneal collagen crosslinking in a 3-stage procedure for keratoconus. J Cataract Refract Surg. 2013;39:722-9.

92. Hashemi H, Miraftab M, Seyedian MA, et al. Long-term results of an accelerated corneal 
cross-linking protocol $\left(18 \mathrm{~mW} / \mathrm{cm}^{2}\right)$ for the treatment of progressive keratoconus. Am J Ophthalmol. 2015;160(6):1164-70.

93. Sherif AM. Accelerated versus conventional corneal collagen cross-linking in the treatment of mild keratoconus: a comparative study. Clin Ophthalmol. 2014;8:1435-40.

94. Yıldirım Y, Olcucu O, Gunaydin ZK, et al. Comparison of accelerated corneal collagen cross-linking types for treating keratoconus. Curr Eye Res. 2017;30:1-5.

95. Alnawaiseh M, Rosentreter A, Böhm MR, Eveslage M, Eter N, Zumhagen L. Accelerated $\left(18 \mathrm{~mW} / \mathrm{cm}^{2}\right)$ corneal collagen cross-linking for progressive keratoconus. Cornea. 2015;34(11):1427-31.

96. Tomita M, Mita M, Huseynova T. Accelerated versus conventional corneal collagen crosslinking. J Cataract Refract Surg. 2014;40(6):1013-20.

97. Ozgurhan EB, Celik U, Bozkurt E, Demirok A. Evaluation of subbasal nerve morphology and corneal sensation after accelerated corneal collagen cross-linking treatment on keratoconus. Curr Eye Res. 2015;40(5):484-9.

98. Hashemian H, Jabbarvand M, Khodaparast M, Ameli K. Evaluation of corneal changes after conventional versus accelerated corneal cross-linking: a randomized controlled trial. J Refract Surg. 2014;30(12):837-42.

99. Ng AL, Chan TC, Cheng AC. Conventional versus accelerated corneal collagen cross-linking in the treatment of keratoconus. Clin Exp Ophthalmol. 2016;44(1):8-14.

100. Razmjoo H, Peyman A, Rahimi A, Modrek HJ. Cornea collagen cross-linking for keratoconus: a comparison between accelerated and conventional methods. Adv Biomed Res. 2017;22(6):10.

101. Cinar Y, Cingü AK, Türkcü FM, et al. Comparison of accelerated and conventional corneal collagen cross-linking for progressive keratoconus. Cutan Ocul Toxicol. 2014;33(3):218-22.

102. Choi M, Kim J, Kim EK, Seo KY, Kim TI. Comparison of the conventional Dresden protocol and accelerated protocol with higher ultraviolet intensity in corneal collagen cross-linking for keratoconus. Cornea. 2017;36(5):523-9.

103. Shetty R, Nagaraja H, Jayadev C, Pahuja NK, Kurian Kummelil M, Nuijts RMMA. Accelerated corneal collagen cross-linking in paediatric patients: two-year follow-up results. BioMed Res 2014;2014:894095. doi:10.1155/2014/894095.
104. Sadoughi MM, Einollahi B, Baradaran-Rafii A, Roshandel D, Hasani H, Nazeri M. Accelerated versus conventional corneal collagen cross-linking in patients with keratoconus: an intrapatient comparative study. Int Ophthalmol. 2016. doi:10.1007/ s10792-016-0423-0.

105. Cummings AB, McQuaid R, Naughton S, Brennan E, Mrochen M. Optimizing corneal cross-linking in the treatment of keratoconus: a comparison of outcomes after standard and high intensity protocols. Cornea. 2016;35(6):814-22.

106. Ng AL, Chan TC, Lai JS, Cheng AC. Comparison of the central and peripheral corneal stromal demarcation line depth in conventional versus accelerated collagen cross-linking. Cornea. 2015;34(11):1432-6.

107. Kymionis GD, Tsoulnaras KI, Liakopoulos DA, Skatharoudi CA, Grentzelos MA, Tsakalis NG. Corneal stromal demarcation line depth following standard and a modified high intensity corneal cross-linking protocol. J Refract Surg. 2016;32(4):218-22.

108. Kamiya K, Shimizu K, Kobashi H, et al. Three-year follow-up of posterior chamber toric phakic intraocular lens implantation for the correction of high myopic astigmatism in eyes with keratoconus. Br J Ophthalmol. 2015;99:177-83.

109. Nanavaty MA, Lake DB, Daya SM. Outcomes of pseudophakic toric intraocular lens implantation in keratoconic eyes with cataract. J Refract Surg. 2012;28(12):884-9.

110. Peyman A, Nouralishahi A, Hafezi F, Kling S, Peyman M. Stromal demarcation line in pulsed versus continuous light accelerated corneal cross-linking for keratoconus. J Refract Surg. 2016;32:206-8.

111. Mazzotta C, Traversi C, Paradiso AL, et al. Pulsed light accelerated crosslinking vs continuous light accelerated crosslinking: one-year results. J Ophthalmol. 2014;2014:604731. doi:10.1155/2014/604731.

112. Park YM, Kim HY, Lee JS. Comparison of 2 different methods of transepithelial corneal collagen cross-linking: analysis of corneal histology and hysteresis. Cornea. 2017;36(7):860-5.

113. Kissner A, Spoerl E, Jung R, Spekl K, Pillunat LE, Raiskup F. Pharmacological modification of the epithelial permeability by benzalkonium chloride in UVA/riboflavin corneal collagen cross-linking. Curr Eye Res. 2010;35(8):715-21.

114. Armstrong BK, Lin MP, Ford MR, et al. Biological and biomechanical responses to traditional epithelium-off and transepithelial riboflavin-UVA CXL techniques in rabbits. J Refract Surg. 2013;29(5):332-41. 
115. Caporossi A, Mazzotta C, Baiocchi S, Caporossi T, Paradiso AL. Transepithelial corneal collagen crosslinking for keratoconus: qualitative investigation by in vivo HRT II confocal analysis. Eur J Ophthalmol. 2012;22(Suppl 7):S81-8.

116. Seiler TG, Fischinger I, Senfft T, Schmidinger G, Seiler T. Intrastromal application of riboflavin for corneal crosslinking. Invest Ophthalmol Vis Sci. 2014;55(7):4261-5.

117. Dong Z, Zhou X. Collagen cross-linking with riboflavin in a femtosecond laser created pocket in rabbit corneas: 6-month results. Am J Ophthalmol. 2011;152(1):22-7.

118. Eljarrat-Binstock E, Domb AJ. Iontophoresis: a non-invasive ocular drug delivery. J Controlled Release. 2006;110(3):479-89.

119. Jouve L, Borderie V, Sandali O, et al. Conventional and iontophoresis corneal cross-linking for keratoconus: efficacy and assessment by optical coherence tomography and confocal microscopy. Cornea. 2017;36(2):153-62.

120. Lombardo M, Giannini D, Lombardo G, Serrao S. Randomized controlled trial comparing transepithelial corneal cross-linking using iontophoresis with the Dresden protocol in progressive keratoconus. Ophthalmology. 2017;124(6):804-12.
121. Bonnel S, Berguiga M, De Rivoyre B, et al. Demarcation line evaluation of iontophoresis-assisted transepithelial corneal collagen cross-linking for keratoconus. J Refract Surg. 2015;31(1):36-40.

122. Mazzotta C, Moramarco A, Traversi C, Baiocchi S, Iovieno A, Fontana L. Accelerated corneal collagen cross-linking using topography-guided UV-A energy emission: preliminary clinical and morphological outcomes. J Ophthalmol. 2016;2016:2031031.

123. Nordström M, Schiller M, Fredriksson A, Behndig A. Refractive improvements and safety with topography-guided corneal crosslinking for keratoconus: 1-year results. Br J Ophthalmol. 2017;101(7):920-5.

124. Lie J, Droutsas K, Ham L, et al. Isolated Bowman layer transplantation to manage persistent subepithelial haze after excimer laser surface ablation. J Cataract Refract Surg. 2010;36(6):1036-41.

125. van Dijk K, Parker J, Tong CM, et al. Midstromal isolated Bowman layer graft for reduction of advanced keratoconus: a technique to postpone penetrating or deep anterior lamellar keratoplasty. JAMA Ophthalmol. 2014;132(4):495-501.

126. van Dijk K, Liarakos VS, Parker J et al. Bowman layer transplantation to reduce and stabilize progressive, advanced keratoconus. Ophthalmology. 2015;122(5):909-17. 